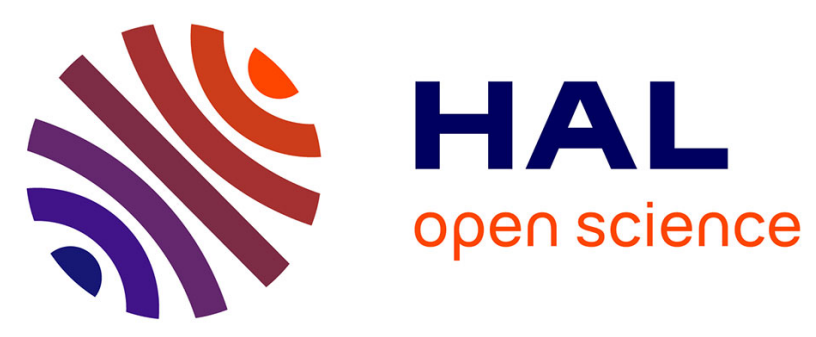

\title{
Facile Ionic Liquid-Assisted Strategy for Direct Precipitation of Eu2+ -Activated Nanophosphors under Ambient Conditions
}

\author{
Huayna Terraschke, Jacob Olchowka, Eugenie Geringer, Aline Varella
}

Rodrigues, Claudia Wickleder

\section{To cite this version:}

Huayna Terraschke, Jacob Olchowka, Eugenie Geringer, Aline Varella Rodrigues, Claudia Wickleder. Facile Ionic Liquid-Assisted Strategy for Direct Precipitation of Eu2+ -Activated Nanophosphors under Ambient Conditions. Small, 2018, 14 (17), pp.1703707. 10.1002/smll.201703707 . hal-02143201

\author{
HAL Id: hal-02143201 \\ https://hal.science/hal-02143201
}

Submitted on 28 Jan 2021

HAL is a multi-disciplinary open access archive for the deposit and dissemination of scientific research documents, whether they are published or not. The documents may come from teaching and research institutions in France or abroad, or from public or private research centers.
L'archive ouverte pluridisciplinaire HAL, est destinée au dépôt et à la diffusion de documents scientifiques de niveau recherche, publiés ou non, émanant des établissements d'enseignement et de recherche français ou étrangers, des laboratoires publics ou privés. 
DOI: $10.1002 /$ ((please add manuscript number))

Full Paper

\section{Facile ionic liquid-assisted strategy for direct precipitation of $\mathrm{Eu}^{2+}$-activated nanophosphors} under ambient conditions

Dr. Huayna Terraschke ${ }^{\dagger}$, Dr. Jacob Olchowka ${ }^{\dagger} \perp$, Eugenie Geringer ${ }^{\dagger}$, Dr.Aline Varella Rodrigues $^{\dagger}$, and Prof. Dr. Claudia Wickleder ${ }^{\dagger} *$

${ }^{\dagger}$ Inorganic Chemistry, School of Science and Technology, University of Siegen, AdolfReichwein-Str. 2, 57068 Siegen, Germany. E-mail: wickleder@ chemie.uni-siegen.de

${ }^{\perp}$ Université de Genève, Dpt. Chimie Physique, 30 Quai Ernest Ansermet, 1211 Genève, Switzerland

Keywords: nanoparticles, ionic liquids, divalent europium, sonochemistry, microwave chemistry

ABSTRACT: This work describes a novel ionic liquid assisted synthesis strategy for a direct and easy production of $\mathrm{Eu}^{2+}$-doped nanoparticles (NPs), where the ionic liquids are also used as fluoride sources to avoid the use of elemental fluorine or toxic HF. Because of the general remarkable advantages of $\mathrm{Eu}^{2+}$ containing phosphors and the additional ones of nanoscaled

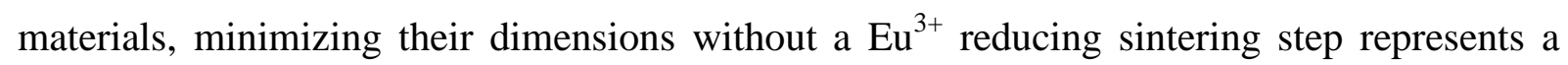




\section{WILEY-VCH}

major advance in this field. Up to now, the direct synthesis of $\mathrm{Eu}^{2+}$-doped nanophosphors consisted of an enormous challenge, due to the oxidation to $\mathrm{Eu}^{3+}$ observed in hydrous solution, which is commonly used for the preparation of NPs, generating lattice defects and undesired particle growth or agglomeration by additional reducing steps at high temperatures. In contrast, ionic liquids do not present an oxidizing character, as long as they do not contain oxidizing ions such as $\mathrm{ClO}_{4}{ }^{-}$or $\mathrm{NO}_{3}{ }^{-}$, allowing the direct precipitation of NPs e.g. using $\mathrm{Eu}^{2+}$ containing starting materials. Here, the undoped and $\mathrm{Eu}^{2+}$-doped $\mathrm{BaFCl} \mathrm{NPs}$ have been prepared under atmospheric conditions for the first time using ionic liquids (ILs) as solvents and also as fluoride source, applying sonochemical and microwave-assisted approaches. In general, this method bears an enormous potential for an easy synthesis of fluoride materials compared to inconvenient solid-state methods. In addition, the ionic liquid plays the role of strongly attached protecting shell which represents $\sim 7-8 \%$ of the total NPs weight.

\section{Introduction}

Inorganic phosphors doped with divalent europium are widely used in different applications and especially as materials used in White Light Emitting Diodes (WLED). ${ }^{[1]}$ They are extremely advantageous because of their high brightness, tunable emission wavelength from UV to red and low toxicity. ${ }^{[2,3]}$ In general, these materials are characterized by strong emission bands upon direct excitation, caused by the parity allowed electronic transitions from the $4 \mathrm{f}^{6} 5 \mathrm{~d}^{1}$ excited states into the $4 \mathrm{f}^{7}$ ground state, strongly influenced by the host lattice. ${ }^{[4,5]}$ In particular, barium fluoride chloride activated with divalent europium is a widely investigated luminescent compound, especially because its outstanding X-ray storage properties ${ }^{[6]}$ and emission bands peaking in the UV-blue spectral range ${ }^{[7,8]}$. Different mechanisms are proposed for explaining the X-ray absorption and visible emission properties after photostimulation in this material. These involve formation of (i) F-centers as electron traps or (ii) hole centers, (iii) interaction of the $\mathrm{Eu}^{2+}$ ions with each of the two centers 
individually and (iv) interaction of the $\mathrm{Eu}^{2+}$ ions with both $\mathrm{F}$ - and hole-centers as intermediate states. $^{[7,8]}$

However, most of the currently available literature about $\mathrm{Eu}^{2+}$-activated $\mathrm{BaFCl}$ report about the synthesis and characterization of micrometer-sized crystals. ${ }^{[7-10]}$ These so-called bulk phosphors are usually prepared by means of solid-state reactions, requiring high temperatures and long reaction times. Nanosized luminescent materials, on the other hand, have gained increase importance in technical applications in the past few years, due to their several advantages in comparison to analogue bulk materials. ${ }^{[2]}$ Chemical and physical properties of nanoparticles (NPs) differ from that of bulk materials, particularly because of quantum size effects, ${ }^{[6]}$ their high surface-to-volume ratio, low light scattering and high packing density. ${ }^{[11]}$ Therefore, smaller amounts of luminescent material are required to build homogeneous and dense coating layers employing nanophosphors, in comparison to compounds of larger crystal sizes, leading to resources saving devices with improved optical properties. Due to these reasons, luminescent nanomaterials play an essential role in the development of displays, UVabsorbers, pigments, luminescent and photo-/electro chromic materials ${ }^{[2,12]}$. Nevertheless, most of the synthesis methods applied for preparing $\mathrm{Eu}^{2+}$ containing nanoscaled compounds are carried out in aqueous solution, requiring a post-synthetic annealing step, in order to fully reduce the oxidation state of europium from $3+$ to $2+.{ }^{[13]}$ Because high temperatures are necessary for this procedure, an undesired coalescence of the particles occurs, resulting in an increase of the particle diameter or the formation of hard agglomerates. In addition, the reduction of $\mathrm{Eu}^{3+}$ to $\mathrm{Eu}^{2+}$ also causes the formation of lattice defects, in general leading to luminescence quenching.

For preparing $\mathrm{BaFCl}: \mathrm{Eu}$ nanostructures, only few synthesis methods have been reported before. $^{[7,8,14]} \mathrm{Ju}$ et al., ${ }^{[14]}$ for instance, have developed a mild-temperature solvothermal method using a mixture of water and ethanol for synthesizing nanocrystalline $\mathrm{BaFCl}: \mathrm{Eu}^{3+}$. ${ }^{[14]}$ Nonetheless, the obtained nanoflakes present 100-200 nm in diameter, 20-40 $\mathrm{nm}$ in thickness, 


\section{WILEY-VCH}

and would require an additional reducing sintering step for reaching the divalent oxidation state of europium. Another interesting strategy is the $\mathrm{BaFCl}: \mathrm{Eu}^{2+} \mathrm{NP}$ precipitation from an aqueous solution of $\mathrm{BaCl}_{2}, \mathrm{EuCl}_{3}$ and $\mathrm{NH}_{4} \mathrm{~F} \cdot{ }^{[7,8]}$ In this case, reducing the europium ions from the trivalent to the divalent oxidation states was achieved by passing the $\mathrm{EuCl}_{3}$ solution through a zinc column, before reacting with $\mathrm{BaCl}_{2}$ and $\mathrm{NH}_{4} \mathrm{~F}$ for the formation of $\mathrm{BaFCl}: \mathrm{Eu}^{2+}$. ${ }^{[7,8]}$ The disadvantage in this case is the rather large particle size of $200-300 \mathrm{~nm}$ of the product and the nitrogen working atmosphere. Very recently, $\mathrm{BaFCl}: \mathrm{Eu}^{2+}$ nanofibers were prepared using a mixture of DMF and water, but a quite high annealing temperatures $\left(600^{\circ} \mathrm{C}\right)$ as well as low heating and cooling rate is required in this case. ${ }^{[15]}$ To overcome these obstacles, new and fast synthesis routes are required for doping divalent europium within nanoscaled host materials. A possible solution for this impasse is offered here by ionic liquid (IL)-assisted synthesis methods. ${ }^{16}$

Moreover, another remarkable advantage of our preparation method is that suitable ionic liquids can also be used as fluorine source. ${ }^{16}$ In general, the proper preparation of high quality fluoride materials even in bulk sizes needs the utilization of elemental fluorine or HF as starting compounds, ${ }^{[17-19]}$ which are rather difficult and inconvenient methods. With the use of fluoride containing ionic liquids as solvent and also as starting compound, ${ }^{[20-21]}$ several fluoride materials not limited to phosphors are expected to be accessible via our method as we very recently reported in $[16]$ using $\mathrm{BmimPF}_{6}(\mathrm{Bmin}=1$-Butyl-3-methylimidazolium hexafluorophosphate) as fluoride ion source. In general, fluoridic materials are extremely advantageous for many applications due to their high ionicity and stability.

Ionic liquids are defined as salts, which are liquid below $100^{\circ} \mathrm{C}$ under normal atmospheric conditions. ${ }^{[22]}$ Contrary to most conventional solvents and besides being reductively stable against many ions, including $\mathrm{Eu}^{2+}$ or even metallic lithium, ILs present several additional advantages. Some of these advantages are the tunability of the solvent properties according to 


\section{WILEY-VCH}

the cation or anion composition, low vapor pressure, high polarity, low gas solubility and their simultaneous application as solvent and reactant. ${ }^{[23-25]}$ While the low vapor pressure allows performing reactions at high temperatures e.g. above $200{ }^{\circ} \mathrm{C}$, the high polarity is responsible for the enhanced solubility of reactants. Furthermore, the adhesion of ILs on the NP surface is responsible for the stabilization of the synthesized products, allowing the generation of small particles and avoiding the formation of agglomerates. ${ }^{[23,24]}$ Most important, the formed compounds, which are normally unstable under atmospheric conditions e.g. $\mathrm{Eu}^{2+}$-containing NPs, are protected by the IL against reaction with air or moisture, because of their low gas solubility ${ }^{[21,26]}$ It can be also assumed that the strong attachment of ILs at the particles surfaces prevents quenching general observed due to water molecules attached to the surface of nanoparticles.

In this work, two different, novel routes have been developed to generate $\mathrm{Eu}^{2+}$-doped $\mathrm{BaFCl}$ NPs. Both syntheses were performed in the ionic liquid 1-Butyl-3-methylimidazolium tetrafluoroborate $\left(\mathrm{BmimBF}_{4}\right)$. As explained above, $\mathrm{BmimBF}_{4}$ fulfils multiple excellent functions in these syntheses as stabilizing the particle surface, acting as fluorine source for the reactions as well as coordinating the $\mathrm{Eu}^{2+}$ ions and stabilizing their oxidation state. Moreover, it is shown, that $\mathrm{Eu}^{2+}$ containing compounds can be used directly as starting materials, alternatively, we have also shown that $\mathrm{Eu}^{2+}$ ions can be smartly generated during the reaction using $\mathrm{EuCl}_{3}$ and Eu metal in an appropriate ratio. The outstanding stability of $\mathrm{Eu}^{2+}$ ions in ILs, which has been demonstrated before, ${ }^{[27]}$ allows the direct precipitation of $\mathrm{Eu}^{2+}$-NPs under atmospheric conditions, as described in this work for the first time.

\section{RESULTS AND DISCUSSION}




\section{WILEY-VCH}

As explained in detail in the experimental section, the synthesis in ionic liquids allowed the flexible preparation of undoped (1) and $\mathrm{Eu}^{2+}$-doped $(\mathbf{2}, \mathbf{3}) \mathrm{BaFCl}$ NPs applying different sonochemical approaches as well as $\mathrm{BaFCl}: \mathrm{Eu}^{2+}(4)$ using a microwave technique (Table 1) using the direct addition of $\mathrm{EuSO}_{4}(\mathbf{2}, \mathbf{3})$ or the in situ generation of the dopant (4). X-ray diffraction (XRD) analysis was applied to confirm the formation of the crystal structure of the synthesized compounds 1-4. Figure S1 shows the match of the diffraction patterns measured for the products of both synthesis methods with the calculated pattern of $\mathrm{BaFCl} .{ }^{[28]}$ The good agreement with the calculated patterns also indicate no significant change of the host lattices due to the doping process with divalent europium ions, similar to the results previously reported in the literature. ${ }^{[7]}$

Barium fluoride chloride nanoparticles doped with divalent europium prepared via the sonochemical approach (2) present a relatively narrow size distribution between ca. 20 and $90 \mathrm{~nm}$, where $80 \%$ of the particles are smaller than $40 \mathrm{~nm}$ determined by dynamic light scattering (Fig. S2, red curve), comparable with the transmission electron microscope images of 3 (Fig.1). In contrast, $\mathrm{BaFCl}: \mathrm{Eu}^{2+} \mathrm{NPs}$ prepared via the microwave-assisted technique (4) are characterized by a broader size distribution in the $90-500 \mathrm{~nm}$ range with $70 \%$ of the particles at about $100 \mathrm{~nm}$ (Fig. S2, black curve). This larger particle size is probably explained by the high temperatures reached with the microwave approach, causing the formation of agglomerates. Because of the improved particle size and particle size distribution, the $\mathrm{BaFCl}: \mathrm{Eu}^{2+} \mathrm{NPs}$ produced by the sonochemical techniques were selected for the further characterization of the optical properties described below.

In the examples shown in the Figure 2, undoped (1) and doped (2) barium fluoride chloride nanoparticles are stably suspended in $\mathrm{BminBF}_{4}$. Under day light, both suspensions are colorless. Accordingly, as shown by the reflection spectrum of undoped BaFCl NPs (Fig. S 3), this compound presents reflectance values above $97 \%$ in the visible range and therefore nearly 


\section{WILEY-VCH}

no efficient absorbance in this spectral region. The reflectance decreases in the UV spectral range, with minimum at $47040 \mathrm{~cm}^{-1}$ and an onset at about $42000 \mathrm{~cm}^{-1}$, allowing to estimate the bandgap energy of approximately $5.2 \mathrm{eV}$. The solution of undoped $\mathrm{BaFCl}$ particles dispersed in $\mathrm{BmimBF}_{4}$ displays weak dark blue emission upon excitation with UV light (Fig. 2a) originated by the ionic liquid, $\mathrm{BminBF}_{4}$, while $\mathrm{Eu}^{2+}$-doped barium fluoride chloride particles in $\mathrm{BmimBF}_{4}$ emit efficient bluish white light under UV irradiation (Fig. 2b). The blue emission of $\mathrm{BmimBF}_{4}$ is most probably explained the presence of $\mathrm{C}$-dot in the ionic liquid. ${ }^{29-30}$ They are generated by electrooxidation due to presence of water in $\mathrm{BmimBF}_{4}$ and their photoluminescence is characterized by the broad emission band $\left(\tilde{V}_{e x}=28570 \mathrm{~cm}^{-1}\right.$, blue curve, Fig. S4), extended between approximately 15000 and $28000 \mathrm{~cm}^{-1}$ with maximum at $23255 \mathrm{~cm}^{-1}$ and full width at half maximum (FWHM) of $6075 \mathrm{~cm}^{-1}$. On the other hand, the excitation spectrum of $\mathrm{BminBF}_{4}$ solution $\left(\tilde{v}_{e m}=23255 \mathrm{~cm}^{-1}\right.$, black curve, Fig. S4) consists of a broad band distributed for energies above $24000 \mathrm{~cm}^{-1}$, overlapping with the respective absorption spectrum.

Emission spectra of $\mathbf{2}$ at room temperature are composed mainly by one intense broad band in the UV-blue range, when excited by different energies e.g. $28570 \mathrm{~cm}^{-1}$ and $30300 \mathrm{~cm}^{-1}$ (Fig. 2a). This emission band is distributed between $24000 \mathrm{~cm}^{-1}$ and $28000 \mathrm{~cm}^{-1}$, peaking at 26380 $\mathrm{cm}^{-1}$, with FWHM of $1756 \mathrm{~cm}^{-1}$ and assigned to the $4 \mathrm{f}^{6} 5 \mathrm{~d}^{1} \rightarrow 4 \mathrm{f}^{7}$ electronic transition of $\mathrm{Eu}^{2+}$ ions. ${ }^{[7]}$ This $\mathrm{Eu}^{2+} 4 \mathrm{f}^{6} 5 \mathrm{~d}^{1} \rightarrow 4 \mathrm{f}^{7}$ emission is very similar to the one in the bulk material, ${ }^{[31]}$ however the intense shoulder detected at lower energy in the emission band of bulk material and attributed to $\mathrm{Eu}^{2+}$ luminescence perturbed by an impurity is not observed in this nanomaterial. ${ }^{[31]}$ As observed in Figure 3b, the excitation spectrum of 2 consists of a broad band in the UV spectral range, rising at about $27000 \mathrm{~cm}^{-1}$, with maximum at $36300 \mathrm{~cm}^{-1}$. Due to the low resolution of the excitation band, the Stokes Shift can only be only estimated to about $2500 \mathrm{~cm}^{-1}$ with the assumption that the lowest $5 \mathrm{~d}^{1} 4 \mathrm{f}^{6}\left({ }^{7} \mathrm{~F}_{0}\right)$ state is located at about $2 / 3$ 


\section{WILEY-VCH}

of the first excitation maximum. Several excitation energies (e.g. $25380 \mathrm{~cm}^{-1}$ ) were probed to detect $\mathrm{Eu}^{3+}$ based emission without any success in all cases, which confirms that $\mathrm{Eu}^{2+}$ is not oxidized during the synthesis. ${ }^{[32]}$

The recorded emission spectra allowed to estimate the Commission internationale de l'éclairage (CIE) 1931 color coordinates of $\mathrm{C}$ dots in $\mathrm{BminBF}_{4}(\mathbf{1}, \mathrm{x}=0.1942, \mathrm{y}=0.2009)$ and $\mathrm{BaFCl}: \mathrm{Eu}^{2+}(2, \mathrm{x}=0.2858, \mathrm{y}=0.3580)$ (Fig. S5), in accordance to the emission color shown in Figure 2. The bluish white emission observed for $\mathrm{BaFCl}: \mathrm{Eu}^{2+} \mathrm{NPs}$ are most probably caused by the combination between the high energy band located at 24000$28000 \mathrm{~cm}^{-1}$, assigned to $\mathrm{Eu}^{2+}$ transitions within the $\mathrm{BaFCl}$ lattice and the weak low-energy band at $16000-24000 \mathrm{~cm}^{-1}$, assigned to the interaction between the $\mathrm{Eu}^{2+}$ ions and the ionic liquid coating layer present in the surface of the NPs, as discussed in detail below. This resulting bluish-white light emission is especially advantageous for the production of LEDs for lighting applications. Cooling sample 2 down to $10 \mathrm{~K}$ leads to a slightly narrower emission peak $\left(\mathrm{FWHM}=1198 \mathrm{~cm}^{-1}\right.$, Fig. S6) in comparison to measurements at room temperature. As presented in Figure 4, the emission intensity gradually decreases with increasing temperature, caused by loss of energy by means of non-radiative transitions, also called thermal quenching. Similarly, the intensity of the emission spectra of $\mathbf{2}$ continuously decreases to about $70 \%$ at $650 \mathrm{~K}$ of its room temperature value (Fig. S7).

The room temperature decay time determination of $\mathbf{2}$ shows a double exponential behavior, which can be fitted to $\tau_{1}=82 \mathrm{~ns}$ and $\tau_{2}=333 \mathrm{~ns}$ when the detection is set at $26370 \mathrm{~cm}^{-1}(380$ $\mathrm{nm}$ ) (see Figure $\mathrm{S} 8$ ). These lifetimes are, in general, very fast for $\mathrm{Eu}^{2+}$ based $\mathrm{f} \leftrightarrow \mathrm{d}$ transitions, especially if compared to those of the bulk materials (3300 ns). ${ }^{[31]}$ However, different arguments can explain these values, namely i) in nanoparticles, the boundary effect improves the electron photon coupling leading to additional quenching effects, ii) the ionic liquid attached at the surface of the nanoparticles also exhibits luminescence at $380 \mathrm{~nm}$ via $\pi-\pi^{*}$ 


\section{WILEY-VCH}

transitions which are extremely fast and may cause energy transfer $\mathrm{Eu}^{2+}$ - ILs (most probably the short lifetime $\tau_{1}=82 \mathrm{~ns}$ is attributed to this procedure), ${ }^{[33]}$ iii) the change of refractive index between $\mathrm{BaFCl}: \mathrm{Eu}^{2+}$ and $\mathrm{BmimBF}_{4}$ could also have an incidence on the life time measurements ${ }^{[34]}$, and iv) the higher surface to volume ratio in nanoparticles usually involves increases of the surface defects concentrations leading to shorter decay time via non radiative relaxation processes. However, in our opinion the surface defects in this case is limited due to the shell layer of ionic liquid attached on the surface. In contrast to $\mathrm{BaFBr}: \mathrm{Eu}^{2+}$ nano-cuboids, nearly no emission coming from color centers is detected for our nanoparticles which tends in favor of our hypothesis. ${ }^{[35]}$

In order to study more in detail the thermal stability of the $\mathrm{BmimBF}_{4}$ layer attached on the surface, temperature dependent IR (Fig. 5), Raman and DSC-TG (Fig. 6) measurements were performed. Ba-F and $\mathrm{Ba}-\mathrm{Cl}$ vibrations situated below $600 \mathrm{~cm}^{-1}$ cannot be detected due to the resolution of our IR device, however it can be clearly seen that going from room temperature to $270{ }^{\circ} \mathrm{C}$, the characteristic vibrations of $\mathrm{BmimBF}_{4}{ }^{[36]}$ are still detectable even if the intensity of the peak has been decreased. This Ba-X vibrations have been therefore, additionally detected by Raman spectroscopy (Fig. S9). ${ }^{[37]}$ DSC and TG show that the loss of weight starts at around $280{ }^{\circ} \mathrm{C}$ (which fits to the measurements done for the raw $\mathrm{BmimBF}_{4}$ ) [38] and at $400^{\circ} \mathrm{C}$ the total weight loss corresponds to $7-8 \%$, which should represent the amount of the IL shell layer in our nanoparticles. The slight gain in mass at the beginning of the heating process consists of an artefact from the thermogravimetry device, most probably caused by the gas flux, not stable at the beginning of the measurement. These results show that the ionic liquid is strongly attached to the surface and hence, these nanoparticles can be seen as core-shell nanoparticles.

\section{Conclusion}




\section{WILEY-VCH}

In conclusion, the direct precipitation of $\mathrm{Eu}^{2+}$-doped nanoparticles from $\mathrm{Eu}^{2+}$-starting materials as well as the direct synthesis from $\mathrm{Eu}^{3+}$ starting materials and Eu metals was reached under atmospheric conditions by two different synthesis approaches, reported in this work using ionic liquids for the first time. For this purpose, the outstanding chemical and physical properties of ionic liquids were explored for stabilizing the oxidation state of divalent europium. The two different applied synthesis techniques were based on an ultrasound- and on a microwave assisted method. Moreover, the application of suitable ionic liquids as suitable fluoride source avoiding the usage of elemental fluorine or $\mathrm{HF}$ for $\mathrm{Eu}^{2+}$ doped fluoride nanoparticles is demonstrated. Samples prepared by the sonochemical approach present a narrower size distribution in comparison to the microwave-based ones. Emission spectra of $\mathrm{BaFCl}: \mathrm{Eu}^{2+} \mathrm{NPs}$ are composed by one main broad band with maximum at 26376 $\mathrm{cm}^{-1}$ and assigned to the $4 \mathrm{f}^{6} 5 \mathrm{~d}^{1} \rightarrow 4 \mathrm{f}^{7}$ electronic transition of $\mathrm{Eu}^{2+}$. This method of using ILs as fluorine source represents an extremely promising alternative synthesis technique for other nanoscaled $\mathrm{Eu}^{2+}$-doped and undoped compounds, especially fluorides, probably leading to a renaissance of fluoride functional materials. The protective shell layer of ionic liquid attached on the surface of the nanoparticles is stable up to $280{ }^{\circ} \mathrm{C}$, represents around $7-8 \%$ of the total weight and should prevent the NPs from oxidation. Applying ionic liquids e.g. $\mathrm{BminBF}_{4}$ enhances the safety of the reaction procedure comparing to other fluorine sources e.g. hydrofluoric acid. In general, other imidazolium-based ionic liquids are also very promising since their reducing character is originated by the imidazolium unit. ${ }^{[39]}$ In principle, it is also expected that this synthesis method also work with other alkyl substitution chain and varying the alkyl chain length might allow tuning the particle size. However, this approach is not explored in our work, because increasing the alkyl chain increases the viscosity and decrease the solubility of $\mathrm{BaCl}_{2}$. Finally, to the best of our knowledge, the here presented synthetic approach for nanomaterials doped with $\mathrm{Eu}^{2+}$ is reported for the first time and we hope this 


\section{WILEY-VCH}

work will open a high way for a new type of $\mathrm{Eu}^{2+}$ based inorganic material synthesis, needed for the future WLED.

\section{Experimental Section}

As described above, the ionic-liquid based synthesis allowed a flexible preparation of undoped and doped $\mathrm{BaFCl} \mathrm{NPs}$ applying different approaches. For undoped $\mathrm{BaFCl}(\mathbf{1}), 0.1 \mathrm{~g}$ of barium chloride (Merck KGaA) was dispersed in $2 \mathrm{~mL} \mathrm{BminBF}_{4}$ (IoLiTec Ionic Liquids Technologies $\mathrm{GmbH}$ ) and sonified ( $3 \mathrm{~W}$ ) for 3 min with an ultrasound tip. After sonication, the product was washed several times with ethanol and dried at $70{ }^{\circ} \mathrm{C}$ for $1 \mathrm{~h}$. $\mathrm{BaFCl}: \mathrm{Eu}^{2+}(\mathbf{2})$ was prepared under the same conditions as $\mathbf{1}$, adding, however, $1 \mathrm{~mol} \%$ of $\mathrm{EuSO}_{4}$ to the $\mathrm{BminBF}_{4}$ solution. Europium(II) sulphate was prepared by the reduction of europium(III) oxide (ChemPur Feinchemikalien und Forschungsbedarf $\mathrm{GmbH}$, 99.9\%) with zinc in hydrochloric acid (Fisher Scientific $\mathrm{GmbH}$ ) under argon atmosphere, followed by precipitation of the sulphate with $0.1 \mathrm{M}$ sulphuric acid (Th. Geyer GmbH \& Co. KG). In addition, $\mathrm{BaFCl}: \mathrm{Eu}^{2+} \mathrm{NPs}(\mathbf{3})$ could be also with prepared with the same solution composition as $\mathbf{2}$, but sonifying the solution for 30 minutes in an ultrasound bath (Branson 1210) and using $\mathrm{EuBr}_{2}\left(99.99 \%\right.$, Sigma-Aldrich) instead of $\mathrm{EuSO}_{4}$. Applying the microwave-assisted approach for synthesizing $\mathrm{BaFCl}: \mathrm{Eu}^{2+} \mathrm{NPs}(4), \mathrm{BaCl}_{2}$ (Merck KGaA, $0.05 \mathrm{~g}$ ) was dispersed in $2 \mathrm{~mL} \mathrm{BminBF}_{4}$ (IoLiTec Ionic Liquids Technologies $\mathrm{GmbH}$ ) this time with $1 \mathrm{~mol} \%$ of $\mathrm{EuCl}_{3}$ $\left(1.24 .10^{-3} \mathrm{~g}\right)$ and $\mathrm{Eu}$ metal pieces $\left(7.310^{-4} \mathrm{~g}\right)$ (ChemPur Feinchemikalien und Forschungsbedarf $\mathrm{GmbH}, 99.9 \%$ ) in an appropriate ratio, being heated afterwards in a household microwave six times for 30 seconds, cooling down to room temperature between the single microwave treatments. Europium(III) chloride was previously prepared by solving $\mathrm{Eu}_{2} \mathrm{O}_{3}$ (ChemPur Feinchemikalien und Forschungsbedarf $\left.\mathrm{GmbH}, 99.9 \%\right)$ in hydrochloric acid and drying. The oxidation state $2+$ of the europium ions was achieved by means of the redox interactions between $\mathrm{EuCl}_{3}$ and Eu metal. Subsequently, for all samples the IL was removed 


\section{WILEY-VCH}

by a large extent through centrifuging and washing with ethanol. Both ultrasound- and microwave-assisted approaches were carried out in air. The composition and preparation methods of the different BaFCl NPs are summarized in Table 1.

Photoluminescence investigations at room and low temperatures on solid samples sealed in quartz ampoules were carried out with a Jobin-Yvon fluorescence spectrometer (Fluorolog 3) equipped with two $0.22 \mathrm{~m}$ double monochromators (SPEX, 1680) and a $450 \mathrm{~W}$ Xenon lamp. Cooling down to $10 \mathrm{~K}$ was achieved by a closed cycle He cryostat (Janis Research). Measurements at high temperatures (up to $600 \mathrm{~K}$ ) were carried out with a Jobin-Yvon fluorescence spectrometer (FluoroMax), also equipped with two monochromators and a $150 \mathrm{~W}$ xenon lamp, combined with an attached self-built oven. All emission spectra were corrected for photomultiplier sensitivity, the excitation spectra for lamp intensity and both for the transmission of the monochromators. Powder X-ray diffraction was measured on a D5000 X-ray diffractometer (Siemens) operating at $40 \mathrm{kV}, 30 \mathrm{~mA}$ with $\mathrm{Cu}-\mathrm{K \alpha}$ radiation $(\lambda=0.154178 \mathrm{~nm})$. Dynamic light scattering was measured with aid of a DynaSizer Analysette 12 (Fritsch GmbH). Temperature dependent FTIR experiments on BaFCl:Eu ${ }^{2+}$ were performed with a Biorad Excalibur Instrument equipped with a Specac Golden Gate heatable ATR setup. The spectral resolution was set to $1 \mathrm{~cm}^{-1}$ and the spectra were recorded between 500 and $4000 \mathrm{~cm}^{-1}$. The sample was heated in steps of $10^{\circ} \mathrm{C}$ from $30{ }^{\circ} \mathrm{C}$ to $280{ }^{\circ} \mathrm{C}$. Differential scanning calorimetry data were measured using a NETZSCH STA449 F3 instrument. The measurements were performed under an inert atmosphere of nitrogen with a purge rate of $20 \mathrm{~mL} / \mathrm{min}$. The sample was placed in $\mathrm{Al}_{2} \mathrm{O}_{3}$ crucible covered with a lid to prevent exposure to atmosphere while mounting. Heating rate was set to $10^{\circ} \mathrm{C} / \mathrm{min}$. Powder samples collected after centrifugation was dispersed in ethanol and few drops of the dispersion were drop casted on a carbon-coated copper grid (Formar Carbon film, 200 Mesh). 


\section{WILEY-VCH}

TEM images were taken with a FEI Tecnai G2 Sphera with $100 \mathrm{keV}$ electron beams focused on the sample.

\section{Supporting Information}

Supporting Information is available from the Wiley Online Library or from the author.

Contents: X-ray powder diffractograms, dynamic light scattering measurements, additional (temperature-dependent) reflection, absorption, excitation and emission spectra, CIE 1931 chromaticity diagram and lifetime measurements.

\section{Acknowledgements}

The authors thank the German Research Foundation (SPP 1708 "Material Synthesis near Room Temperature") for financial support.

Received: ((will be filled in by the editorial staff))

Revised: ((will be filled in by the editorial staff)) Published online: ((will be filled in by the editorial staff))

References

[1] P. F. Smet,.J. J. Joos,. Nat. Mater. 2017, 16, 500-501.

[2] H. Terraschke, C. Wickleder, Chem. Rev. 2015, 115, 11352- 11378.

[3] H. Terraschke, M. Suta, M. Adlung, S. Mammadova, N. Musayeva, R. Jabbarov, M. Nazarov, C. Wickleder, J. Spectrosc. 2015, 2015, 541958/1-12.

[4] S. S. M. Poort, G. Blasse, J. Lumin. 1997, 72-74, 247-249.

[5] G. Blasse, B. C. Grabmaier, In Luminescent Materials, $1^{\text {st }}$ ed., Springer-Verlag, Berlin, 1994, pp 20-30.

[6] N. Miura, In Phosphor Handbook, $2^{\text {nd }}$ ed., W. M.Yen, S. Shionoya, H. Yamamoto, Eds.; CRC press, New York; 2007, pp 619-633.

[7] X. Wang, Z. Liu, M. A. Stevens-Kalceff, H. Riesen, Mater. Res. Bull. 2013, 48, 36913694.

[8] V. D'Anna, M. L. Daku,.H. Hagemann, F. Kubel, Phys. Rev. B 2010, 82, 024108/1-11. 


\section{WILEY-VCH}

[9] M. Secu, L. Matei, T. Serban, E. Apostol, G. Aldica, C. Silion, Opt. Mater. 2000, 15, $115-122$.

[10] J. Sytsma, G. Blasse, J. Lumin. 1992, 51, 283-292.

[11] U. Schubert, N. Hüsing, In Synthesis of Inorganic Materials; $2^{\text {nd }}$ Edt., WILEY VCH, Weinheim, 2005, pp 353-355.

[12] D. Vollath, In Nanomaterials: an Introduction to Synthesis, Properties and Application; Wiley-VCH, Weinheim, 2008, p 145.

[13] H. C. Streit, J. Kramer, M. Suta, C. Wickleder, Materials 2013, 6, 3079-3093.

[14] Q. Ju, Y. Liu, R. Li, L. Liu, W. Luo, X. Chen, J. Phys. Chem. C 2009, 113, 2309-2315.

[15] C. Zheng, D. Li, Q. Ma, Y. Song, X. Dong, X. Wang, W. Yu, J. Wang, G. Liu, Chem. Eng. J. 2017, 310, 91-101.

[16] J. Olchowka, M. Suta, C. Wickleder, Chem. Eur. J. 2017, 23, 12092-12095.

[17] X. Quan, S. Yang, X. Ruan, H. Zhao, Environ. Sci. Technol. 2005, 39, 3770-3775.

[18] R. J. Francis, P. S. Halasyamani, D. O'Hare, Chem. Mater. 1998, 10, 3131-3139.

[19] O. Graudejus, S. H. Elder, G. M. Lucier, C. Shen, N. Bartlett, Inorg. Chem. 1999, 38, 2503-2509.

[20] D. S. Jacob, L. Bitton, J. Grinblat, I. Felner, Y. Koltypin, A. Gedanken, Chem. Mater. 2006, 18, 3162-3168.

[21] M. He, P. Huang, C. Zhang, F. Chen, C. Wang, J. Ma, R. He, D. Cui, Chem. Comm. 2011, 47, 9510-9512.

[22] Z. Ma, J. Yu, S. Dai, Adv. Mater. 2010, 22, 261-285.

[23] P. Migowski, J. Dupont, Chem. Eur. J. 2007, 13, 32-39.

[24] G. Machado, J. D. Scholten, T. da Vargas, S. R. Teixeira, L. H. Ronchi, J. Dupont, Int. J. Nanotechnol. 2007, 4, 541-563. 


\section{WILEY-VCH}

[25] J. L. Anderson, J. L. Anthony, J. F.Brennecke, E. J. Maginn, In Ionic liquids in Synthesis, $2^{\text {nd }}$ Edt; Wasserscheid, P., Welton, T., Eds.; WILEY-VCH, Weinheim, 2008, pp 103-129.

[26] D. Freudenmann, S. Wolf, M. Wolff, C. Feldmann, Angew. Chem., Int. Ed. 2011, 50, 11050-11060.

[27] I. Billard, G. Moutiers, A. Labet, A. El Azzi, C. Gaillard, C. Mariet, K. Luetzenkirchen, Inorg. Chem. 2003, 42, 1726-1733.

[28] M. Sauvage, Acta Crystallogr., Sect. B: Struct. Crystallogr. Cryst. Chem. 1974, B30, 2786-2787.

[29] J. Shen, Y. Zhu, X. Yang, C. Li, Chem. Comm. 2012, 48, 3686-3699.

[30] S. N. Baker, G. Baker, Angew. Chem. Int. Ed. 2010, 49, 6726-6744.

[31] M. Secu, C. E. Secu, V. Vasile, D. Predoi, D. M. Gazdaru, J. Optoelectron. Adv. Mater. 2007, 9, 1800-1802.

[32] M. Colmont, S. Saitzek, A. Katelnikovas, H. Kabbour, J. Olchowka, P. Roussel, J. Mater. Chem. C 2016, 4, 7277-7285.

[33] M. A. Bhat, C. K. Dutta, G. M. Rather, J. Molecular Liquids 2013, 181, 142-151.

[34] M. B. Price, J. Butkus, T. C. Jellicoe, A. Sadhanala, A. Briane, J. E. Halpert, K. Broch, J. M. Hodgkiss, R. H. Friend, F. Deschler, Nat. Commun. 2015, 6, 8420.

[35] Q. Liang, Z. Li, W. Ma, Y. Shi, X. Yang, Mater. Res. Bull. 2012, 47, 2357-2363.

[36] Y. Jeon, J. Sung, D. Kim, C. Seo, H. Cheong, Y. Ouchi, R. Ozawa, H. Hamaguchi, J. Phys. Chem. B 2008, 112, 923-928.

[37] J.F. Scott, J. Chem. Phys. 1968, 49, 2766-2769.

[38] W. Feng, Y. Lu, Y. Chen, Y. Lu, T. Yang, J. Therm. Anal. Calorim. 2016, 125, 143154.

[39] L. Zhao, C. Zhang, L. Zhuo, Y. Zhang, J. Y. Ying. J. Am. Chem. Soc. 2008, 130, $12586-12587$. 


\section{WILEY-VCH}

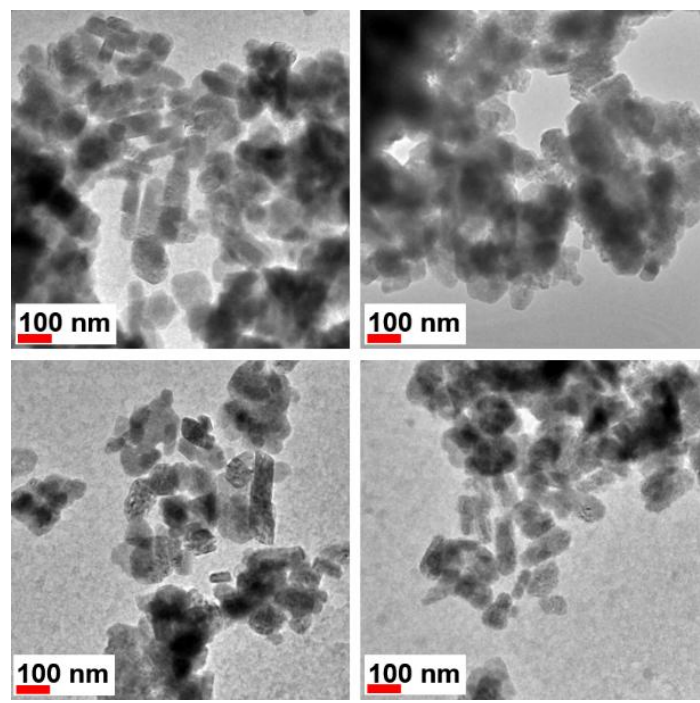

Figure 1. Transmission electron microscope (TEM) images of BaFCl:Eu ${ }^{2+} \mathrm{NPs}(3)$.

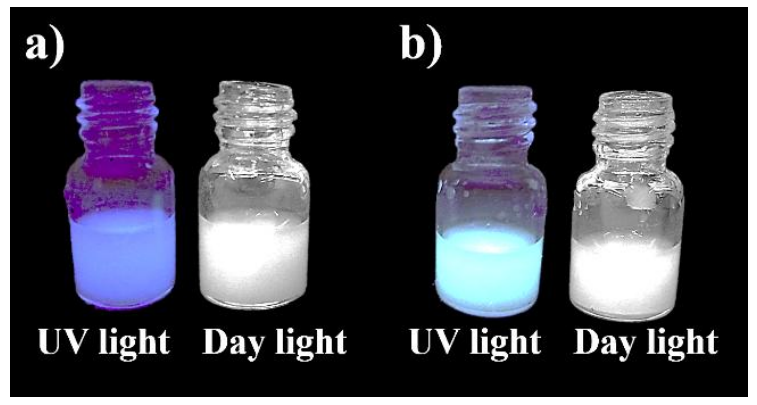

Figure 2. In $\mathrm{BmimBF}_{4}$ suspended nanoparticles of a) $\mathbf{1}$ and b) $\mathbf{2}$ under UV and daylight.

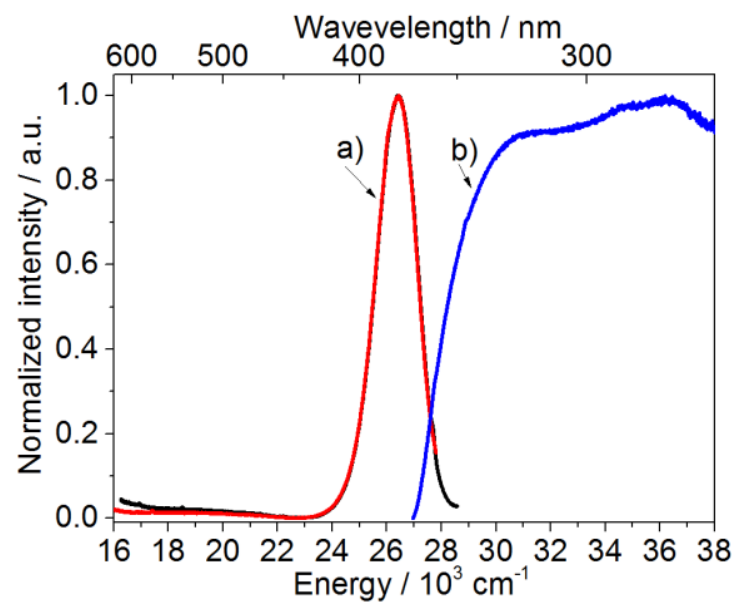




\section{WILEY-VCH}

Figure 3. a) Emission $\left(\tilde{v}_{e x}=28570 \mathrm{~cm}^{-1}\right.$ in red, $\tilde{v}_{e x}=30300 \mathrm{~cm}^{-1}$ in black $)$ and b) excitation spectra $\left(\tilde{v}_{e m}=26375 \mathrm{~cm}^{-1}\right.$ in blue $)$ of 2 at room temperature.

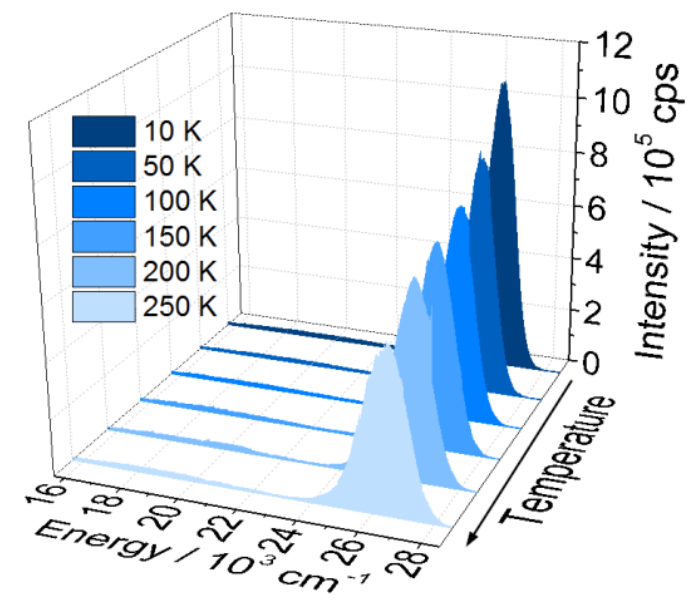

Figure 4. Emission spectra of 2 at low temperatures $\left(\tilde{v}_{e x}=33303 \mathrm{~cm}^{-1}\right)$.
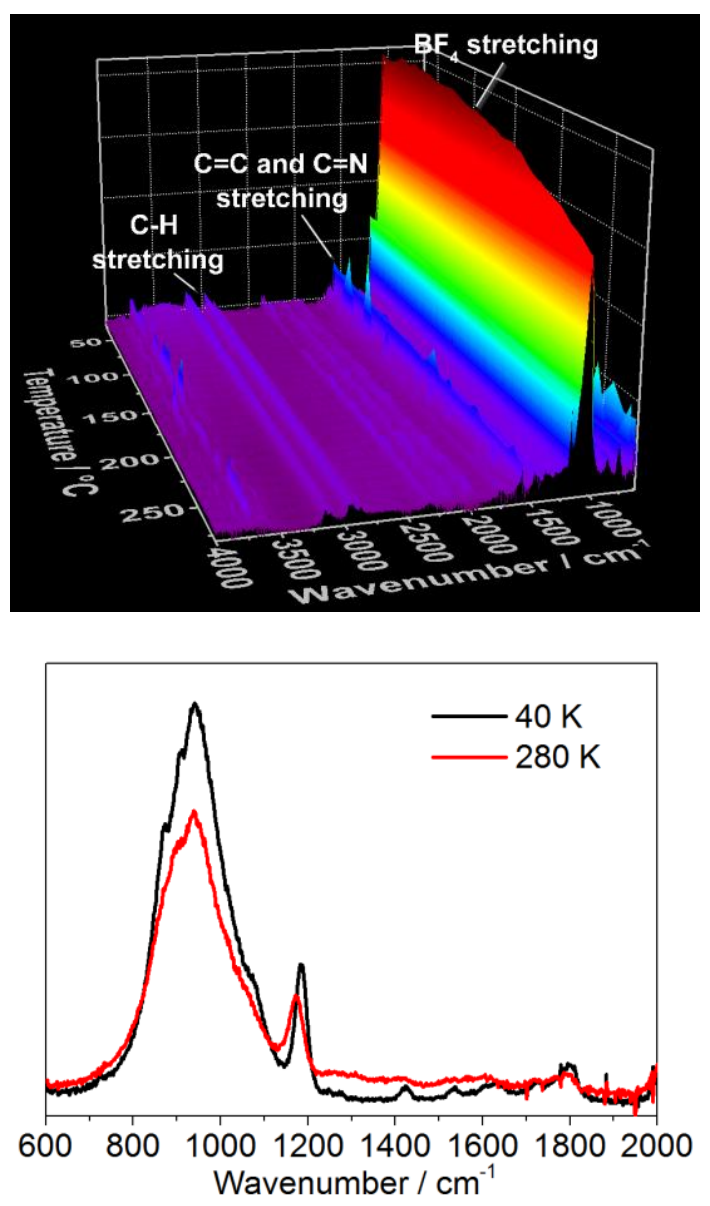


\section{WILEY-VCH}

Figure 5. Top: Temperature dependent IR spectra of the synthesized $\mathrm{BaFCl}: \mathrm{Eu}^{2+} \mathrm{NPs}$ by ultrasound approach (3). Bottom: Comparison of IR spectra of $\mathbf{3}$ recorded at $40 \mathrm{~K}$ and $280 \mathrm{~K}$.

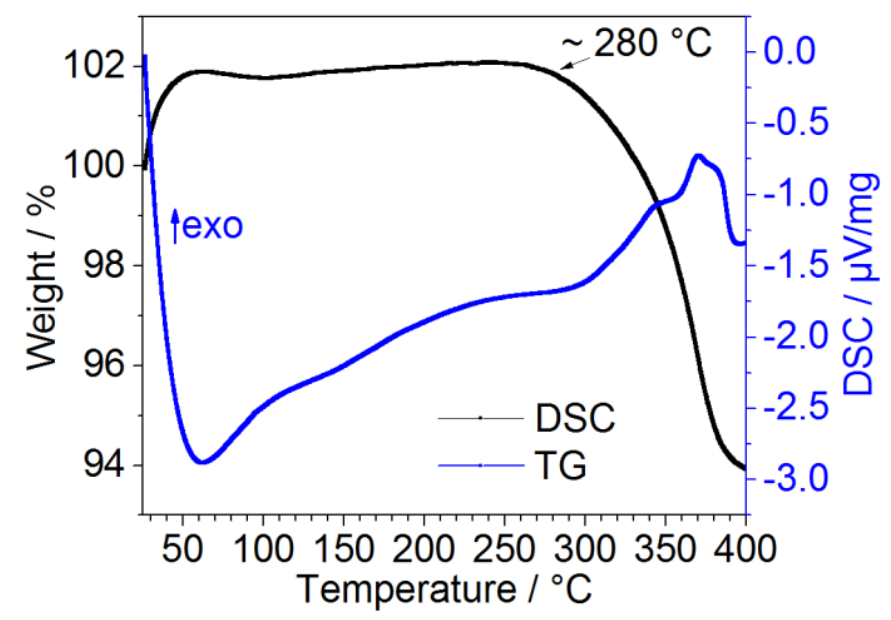

Figure 6. DSC and TG measurements of the synthesized BaFCl:Eu ${ }^{2+} \mathrm{NPs}$ by ultrasound approach (3).

Table 1. Denomination and composition of synthesized BaFCl NPs.

\begin{tabular}{ccccc}
\hline Compound & Composition & $\begin{array}{c}\text { Synthesis } \\
\text { method }\end{array}$ & Reaction time & $\begin{array}{c}\text { Europium } \\
\text { Source }\end{array}$ \\
\hline $\mathbf{1}$ & $\mathrm{BaFCl}$ & Ultrasound tip & $3 \mathrm{~min}$ & - \\
$\mathbf{2}$ & $\mathrm{BaFCl}: \mathrm{Eu}^{2+}$ & Ultrasound tip & $3 \mathrm{~min}$ & $\mathrm{EuSO}_{4}$ \\
$\mathbf{3}$ & $\mathrm{BaFCl}: \mathrm{Eu}^{2+}$ & Ultrasound bath & $30 \mathrm{~min}$ & $\mathrm{EuBr}_{2}$ \\
$\mathbf{4}$ & $\mathrm{BaFCl}: \mathrm{Eu}^{2+}$ & Microwave & $3 \mathrm{~min}$ & $\mathrm{Eu}+\mathrm{EuCl}_{3}$ \\
\hline
\end{tabular}




\section{WILEY-VCH}

The table of contents entry should be 50-60 words long:

Here, the formation of $\mathrm{Eu}^{3+}$ during the synthesis of $\mathrm{Eu}^{2+}$ phosphors is prevented in the relative redox stable ionic liquid $\mathrm{BmimBF}_{4}$ and allows the direct precipitation of NPs from $\mathrm{Eu}^{2+}$ starting materials. $\mathrm{Eu}^{2+}$ nanoparticles (NPs) e.g. $\mathrm{BaFCl} \mathrm{Eu}^{2+}$ have been prepared by means of two different synthetic routes in ILs, in air for the first time.

Keyword: nanoparticles, ionic liquids, divalent europium, sonochemistry, microwave chemistry

Dr. Huayna Terraschke ${ }^{\dagger}$, Dr. Jacob Olchowka ${ }^{\dagger} \perp$, Eugenie Geringer ${ }^{\dagger}$, Dr. Aline Varella Rodrigues ${ }^{\dagger}$, and Prof. Dr. Claudia Wickleder ${ }^{\dagger} *$

Title Facile ionic liquid-assisted strategy for direct precipitation of $\mathrm{Eu}^{2+}$-activated nanophosphors under ambient conditions

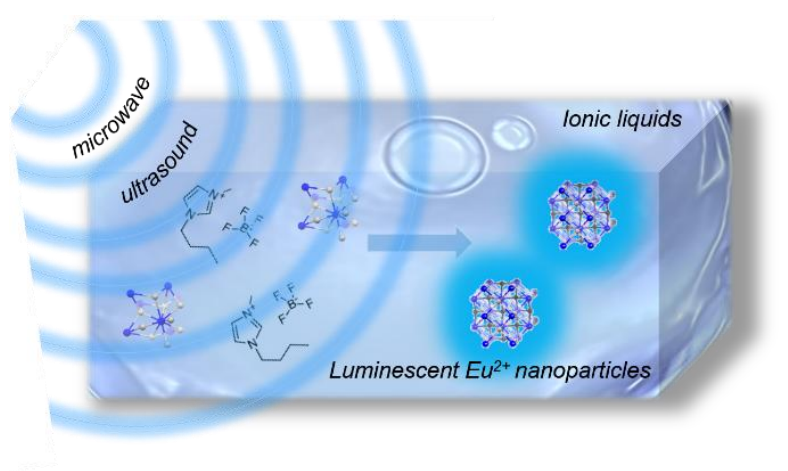

Copyright WILEY-VCH Verlag GmbH \& Co. KGaA, 69469 Weinheim, Germany, 2016. 


\title{
Facile ionic liquid-assisted strategy for direct
}

\author{
precipitation of $\mathrm{Eu}^{2+}$-activated nanophosphors
}

\section{under ambient conditions}

\author{
Dr. Huayna Terraschke $e^{\dagger}$, Dr. Jacob Olchowka ${ }^{\dagger} \perp$, Eugenie Geringer ${ }^{\dagger}$, Dr.Aline Varella \\ Rodrigues ${ }^{\dagger}$, and Prof. Dr. Claudia Wickleder ${ }^{\dagger} *$
}

Figure S1. X-ray diffraction (XRD) analysis of a) undoped $\mathrm{BaFCl}(1)$ and b) $\mathrm{BaFCl}^{-\mathrm{Eu}^{2+}}$ (2) prepared using the ultrasound tip as well as c) $\mathrm{BaFCl}^{2} \mathrm{Eu}^{2+}(\mathbf{3})$ synthesized using the ultrasound bath and d) $\mathrm{BaFCl}: \mathrm{Eu}^{2+}$ (4) prepared using the microwave technique in comparison to e) the calculated diffraction pattern of $\mathrm{BaFCl}$. ${ }^{[1]}$ The impurities $\left({ }^{*}\right)$ in the sample (1) are attributed to undissolved $\mathrm{BaCl}_{2}$

Figure S2. Particle size distribution of $\mathrm{BaFCl}: \mathrm{Eu}^{2+}$ prepared by the sonochemical (2, red curve) and the microwave-assisted (4, black curve) techniques determined with the aid of dynamic light scattering. .21

Figure S3. Reflection spectrum of undoped $\mathrm{BaFCl}$ (1). .22

Figure S4. Excitation ( $\lambda_{\mathrm{em}}=430 \mathrm{~nm}$, black curve), emission $\left(\lambda_{\mathrm{ex}}=350 \mathrm{~nm}\right.$, blue curve) and absorption spectra of $\mathrm{BminBF}_{4}$. .22

Figure S5. Plot of Commission internationale de l'éclairage (CIE) 1931 chromaticity diagram for $\mathrm{BaFCl}_{\mathrm{Eu}}^{2+}\left(\mathbf{2}, \bullet, \mathrm{x}=0.2858, \mathrm{y}=0.3580, \lambda_{\mathrm{ex}}=340 \mathrm{~nm}\right)$ and for $\mathrm{BminBF}_{4}(\boldsymbol{\bullet}, \mathrm{x}=0.1942, \mathrm{y}$ $\left.=0.2009, \lambda_{\mathrm{ex}}=350 \mathrm{~nm}\right)$.

Figure S6. Excitation ( $\lambda_{\mathrm{em}}=380 \mathrm{~nm}$, red curve) and emission spectra at $\lambda_{\mathrm{ex}}=300 \mathrm{~nm}$ (blue curve), $\lambda_{\mathrm{ex}}=330 \mathrm{~nm}$ (black curve) and $\lambda_{\mathrm{ex}}=345 \mathrm{~nm}$ (green curve) of $\mathrm{BaFCl}: \mathrm{Eu}^{2+} \mathrm{NPs}(2) \ldots .23$ Figure S7. Temperature dependence of the emission intensity of $\mathrm{BaFCl}: \mathrm{Eu}^{2+}(2)$ at 26378 $\mathrm{cm}^{-1}\left(379 \mathrm{~nm}, \lambda_{\mathrm{ex}}=300 \mathrm{~nm}\right)$.

Figure S8. Room temperature decay time measurement of 2 with $\lambda_{\mathrm{ex}}=33333 \mathrm{~cm}^{-1}$ and $\lambda_{\mathrm{em}}=$ $26315 \mathrm{~cm}^{-1}\left(R^{2}=0.98\right)$ for the $4 f^{6} 5 d^{1} \rightarrow 4 f^{7}$ electronic transition of $\mathrm{Eu}^{2+}$ 24

Figure S9. Raman spectroscopy result of compound 2 . .25 
WILEY-VCH

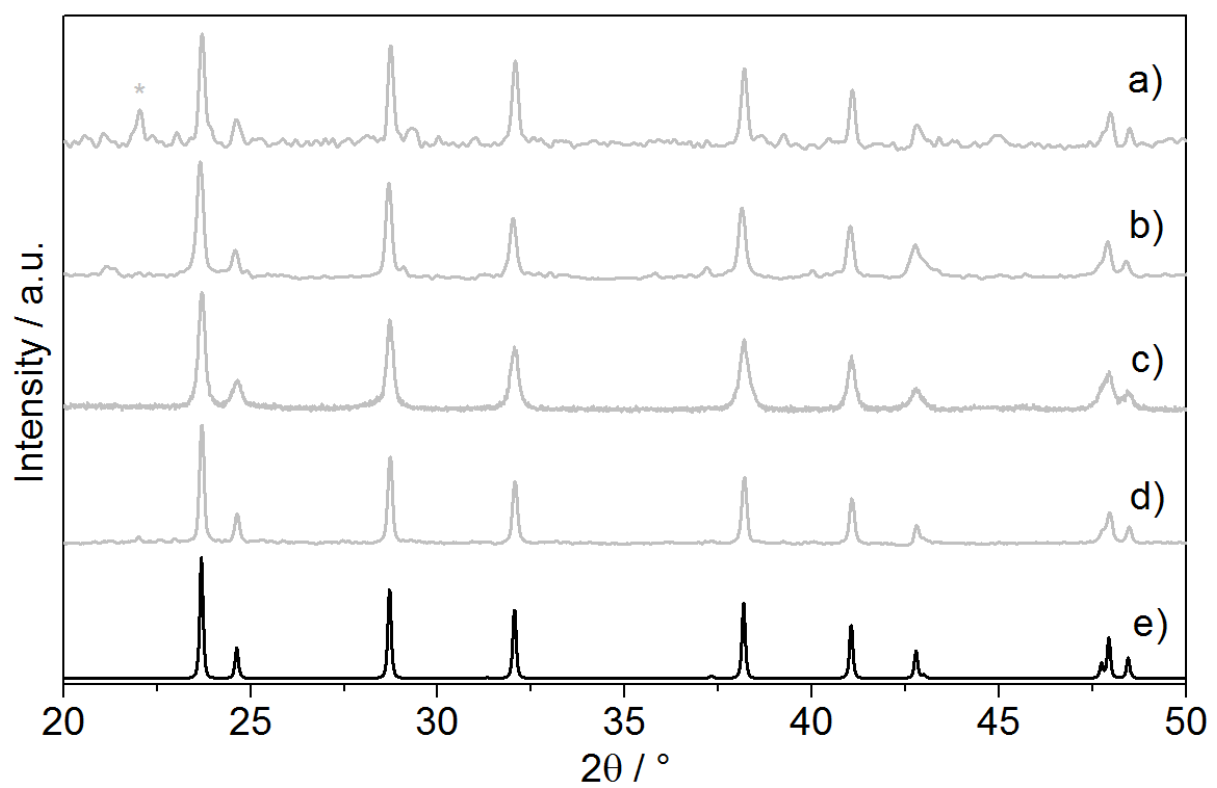

Figure S1. X-ray diffraction (XRD) analysis of a) undoped $\mathrm{BaFCl}(\mathbf{1})$ and b) $\mathrm{BaFCl}^{2} \mathrm{Eu}^{2+}$ (2) prepared using the ultrasound tip as well as c) $\mathrm{BaFCl}^{2} \mathrm{Eu}^{2+}$ (3) synthesized using the ultrasound bath and d) $\mathrm{BaFCl}: \mathrm{Eu}^{2+}$ (4) prepared using the microwave technique in comparison to e) the calculated diffraction pattern of $\mathrm{BaFCl} .{ }^{[1]}$ The impurities $\left({ }^{*}\right)$ in the sample (1) are attributed to undissolved $\mathrm{BaCl}_{2}$.

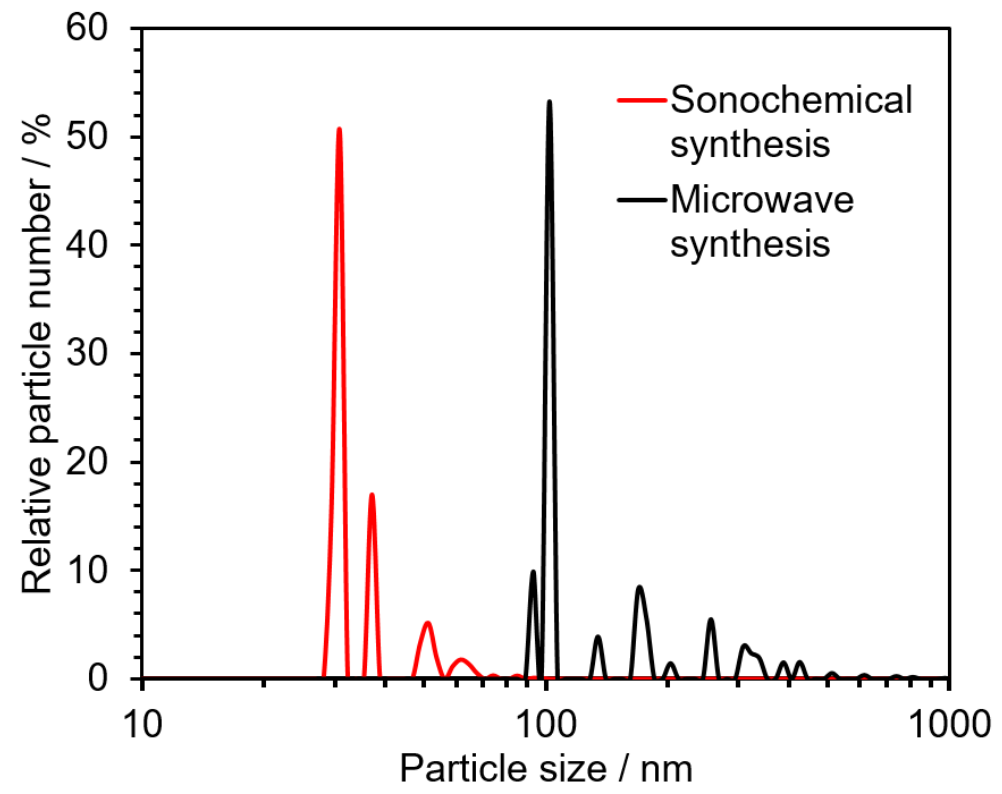

Figure S2. Particle size distribution of $\mathrm{BaFCl}: \mathrm{Eu}^{2+}$ prepared by the sonochemical (2, red curve) and the microwave-assisted (4, black curve) techniques determined with the aid of dynamic light scattering. 


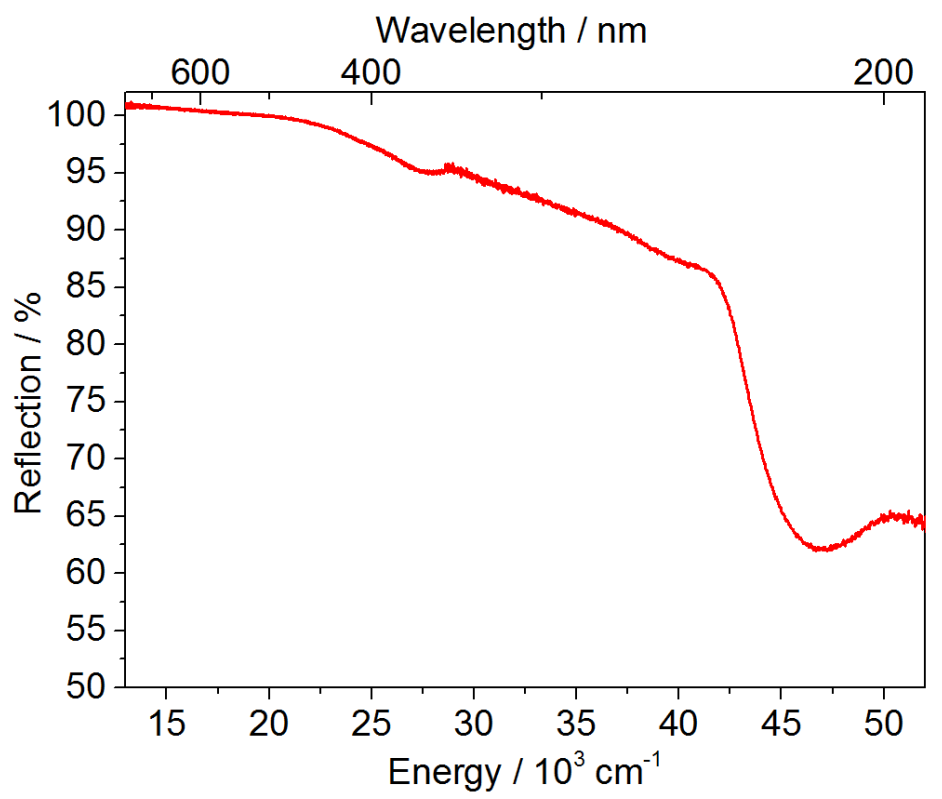

Figure S3. Reflection spectrum of undoped $\mathrm{BaFCl}$ (1).

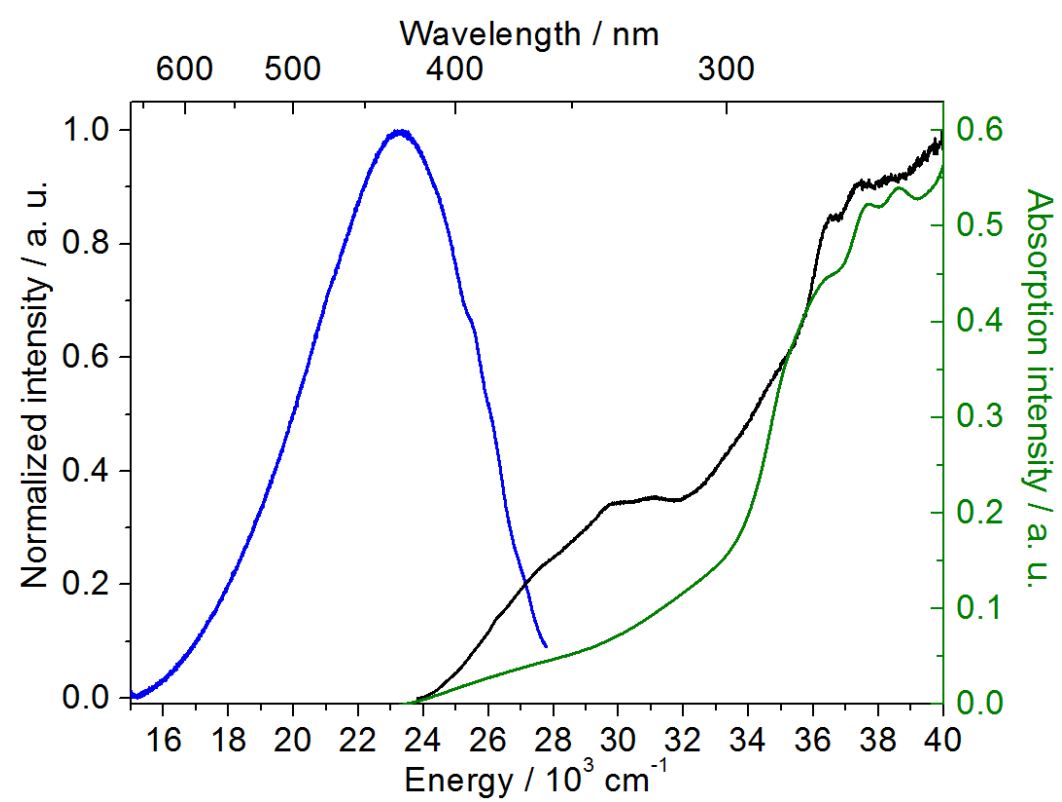

Figure S4. Excitation ( $\lambda_{\mathrm{em}}=430 \mathrm{~nm}$, black curve), emission ( $\lambda_{\mathrm{ex}}=350 \mathrm{~nm}$, blue curve) and absorption spectra of $\mathrm{BminBF}_{4}$. 


\section{WILEY-VCH}

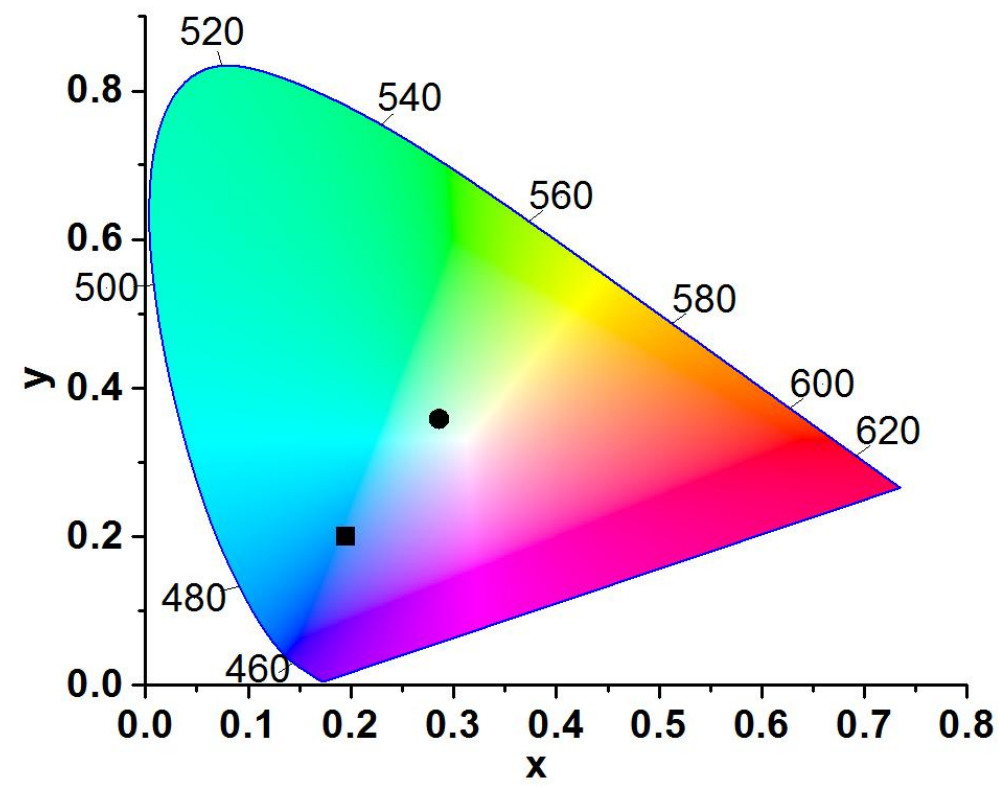

Figure S5. Plot of Commission internationale de l'éclairage (CIE) 1931 chromaticity diagram for $\mathrm{BaFCl}_{\mathrm{Eu}}^{2+}\left(\mathbf{2}, \bullet, \mathrm{x}=0.2858, \mathrm{y}=0.3580, \lambda_{\mathrm{ex}}=340 \mathrm{~nm}\right)$ and for $\mathrm{BminBF}_{4}(\mathbf{m}, \mathrm{x}=0.1942, \mathrm{y}$ $\left.=0.2009, \lambda_{\mathrm{ex}}=350 \mathrm{~nm}\right)$.

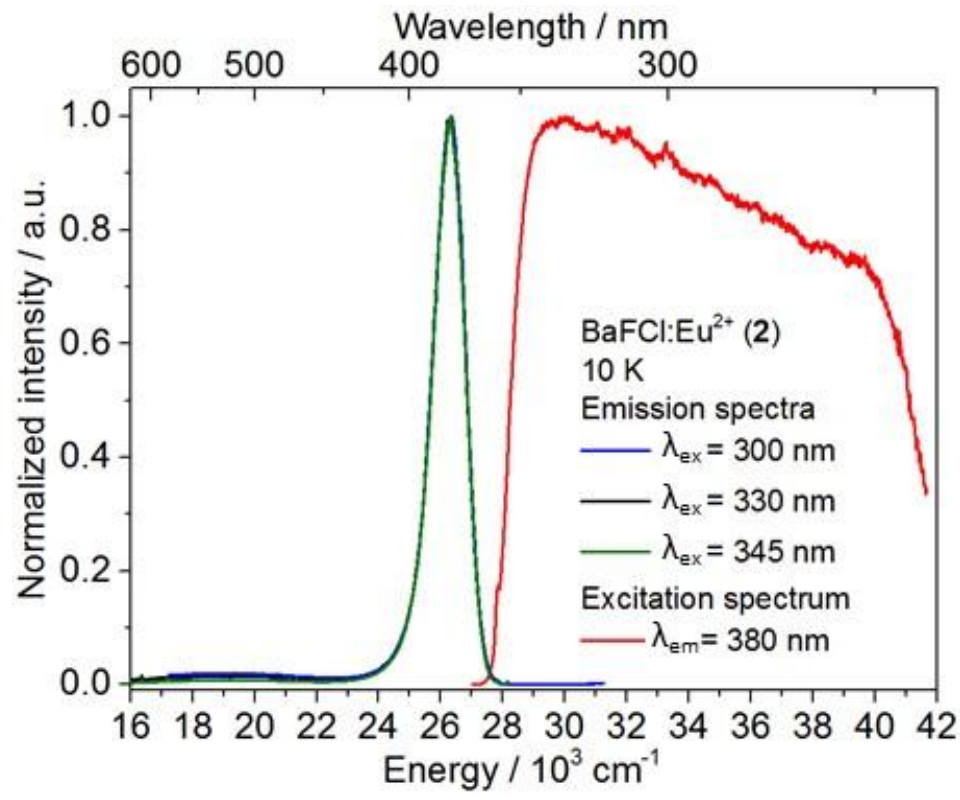

Figure S6. Excitation ( $\lambda_{\mathrm{em}}=380 \mathrm{~nm}$, red curve) and emission spectra at $\lambda_{\mathrm{ex}}=300 \mathrm{~nm}$ (blue curve), $\lambda_{\mathrm{ex}}=330 \mathrm{~nm}$ (black curve) and $\lambda_{\mathrm{ex}}=345 \mathrm{~nm}$ (green curve) of $\mathrm{BaFCl}^{\mathrm{E}} \mathrm{Eu}^{2+} \mathrm{NPs}(2)$. 
WILEY-VCH

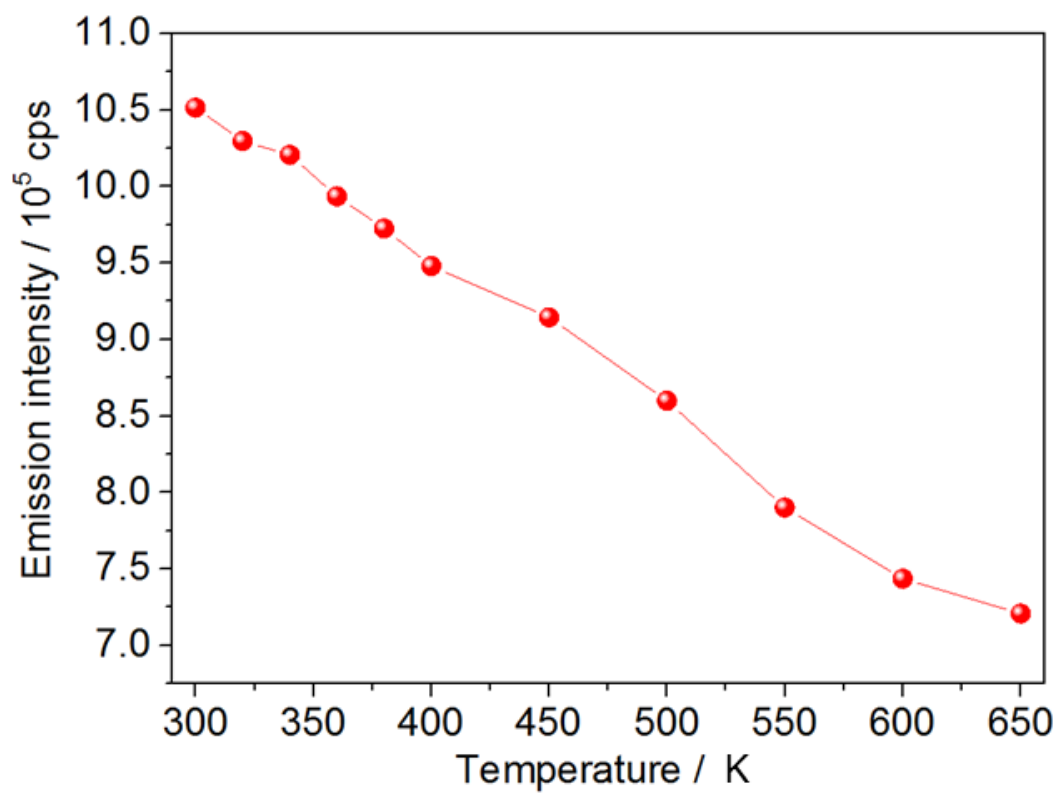

Figure S7. Temperature dependence of the emission intensity of $\mathrm{BaFCl}^{-\mathrm{Eu}^{2+}}(\mathbf{2})$ at 26378 $\mathrm{cm}^{-1}\left(379 \mathrm{~nm}, \lambda_{\mathrm{ex}}=300 \mathrm{~nm}\right)$.

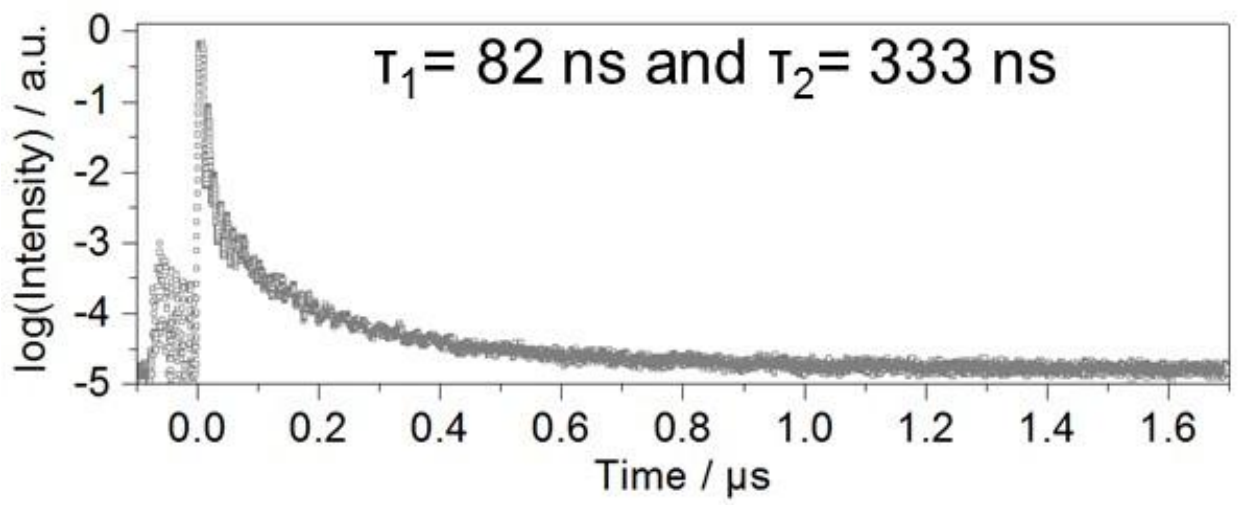

Figure S8. Room temperature decay time measurement of 2 with $\lambda_{\mathrm{ex}}=33333 \mathrm{~cm}^{-1}$ and $\lambda_{\mathrm{em}}=$ $26315 \mathrm{~cm}^{-1}\left(R^{2}=0.98\right)$ for the $4 f^{6} 5 d^{1} \rightarrow 4 f^{7}$ electronic transition of $E u^{2+}$. 


\section{WILEY-VCH}

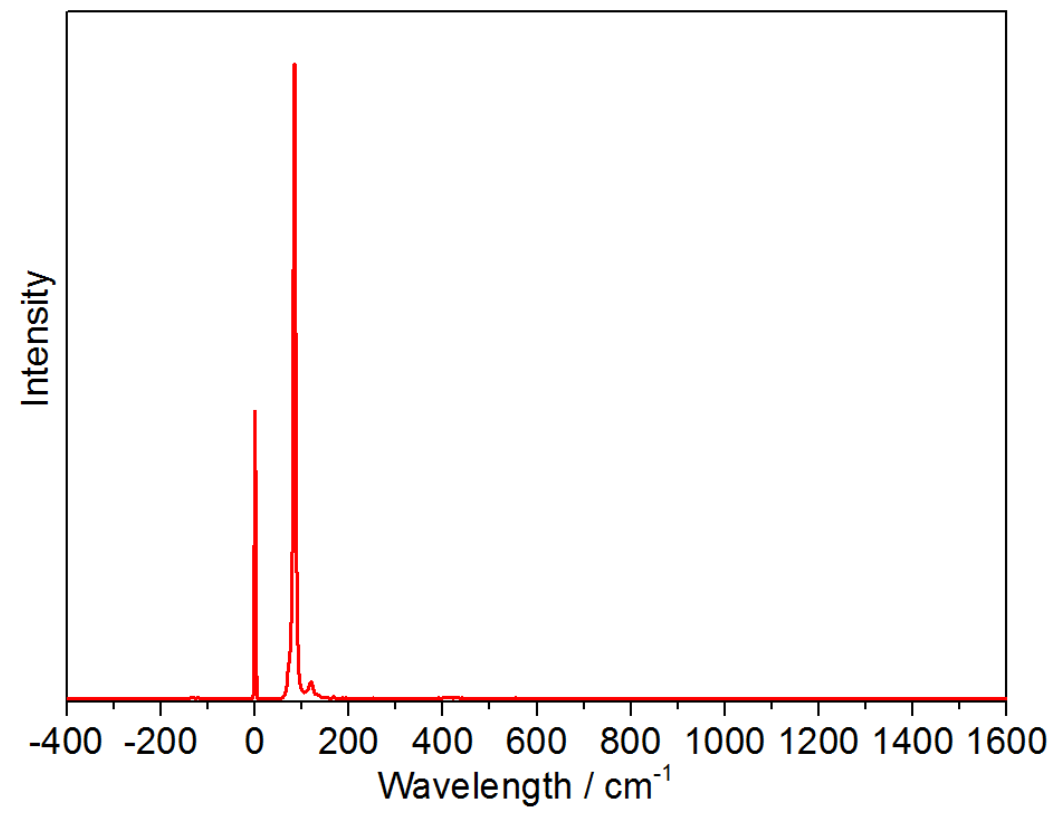

Figure S9. Raman spectroscopy result of compound 2.

\section{References}

[1] M. Sauvage, Acta Crystallographica B (1982, 24,1968-1938) 1974, 30, 2786-2787. 